\title{
A CULTURA ORGANIZACIONAL EM UMA INSTITUIÇÃO DE ENSINO SUPERIOR PRIVADO, NA PERSPECTIVA DE DIFERENTES PÚBLICOS
}

\author{
THE ORGANIZATIONAL CULTURE IN A PRIVATE HIGHER \\ EDUCATION INSTITUTION IN THE PERSPECTIVE OF \\ DIFFERENT PUBLIC
}

\section{LA CULTURA ORGANIZACIONAL EN UNA INSTITUCIÓN DE EDUCACIÓN SUPERIOR PRIVADO EN LA PERSPECTIVA DIFERENTE PÚBLICOS}

\author{
Magéla Duarte Just \\ Mestre em Administração pela Imed Business School, \\ Brasil \\ magelajust@gmail.com

\section{Claudete Batistella} \\ Mestre em Administração pela Imed Business School, \\ Brasil \\ claudetebatistella1@gmail.com
}

\author{
Contextus \\ ISSNe 2178-9258 \\ Organização: Comitê Científico Interinstitucional \\ Editor Científico: Diego de Queiroz Machado \\ Avaliação: double blind review pelo SEER/OJS \\ Edição de texto e de layout: Carlos Daniel Andrade \\ Recebido em 06/03/2017 \\ Aceito em 26/02/2018 \\ $2^{\mathrm{a}}$ versão aceita em 17/04/2018
}

\section{Elaine Taufer}

Mestranda em Administração pela Imed Business School, Brasil

elaine.taufer@gmail.com

Janaína Macke

Professora do PPGA IMED Business School e Universidade de Caxias do Sul (UCS), Brasil

janaina.macke@gmail.com

\section{RESUMO}

As organizações compõem-se de diferentes públicos que interagem entre si, formando sua cultura organizacional (CO). Esta investigação analisa a CO de uma IES privada - a IMED -, na perspectiva de professores, técnicoadministrativos e alunos. Sua natureza é quantitativa e estatístico-descritiva, adotando o IBACO - Instrumento Brasileiro para Avaliação da Cultura Organizacional, adaptado. Resultados sugerem que a cultura daquela IES manifesta sua boa interação com o público interno e com as forças sociais, promovendo ambiente de convivência agradável. Há coerência entre os valores analisados e os da IMED, assim como diferenças na percepção de valores e práticas da IES entre os públicos. A limitação da pesquisa evidencia-se em ter sido realizada em uma única IES. Este estudo auxiliará gestores a traçarem estratégias de atuação, fortalecendo sua CO, e contribui para o avanço nas pesquisas sobre $\mathrm{CO}$, ao propor a adaptação do IBACO ao contexto de IES privadas.

Palavras-chave: Cultura Organizacional. Instituição de Ensino Superior. Valores e Práticas.

\begin{abstract}
Organizations consist of different audiences that interact with each other, forming the organizational culture (OC). This investigation analyzes the $\mathrm{OC}$ of a private higher education institution (HEI) - IMED — from the perspective of teachers, technical-administrative personnel, and students. It is a quantitative study with descriptive statistics, which used an adapted version of the Brazilian Instrument for Evaluation of Organizational Culture (IBACO). The results suggest that the culture of the mentioned HEI manifests good interaction with the internal audience and the social forces, promoting a pleasant environment. There is consistency between the values analyzed and those of IMED, but there are differences of perception with respect to the values and practices of the HEI among audiences.
\end{abstract}


The research is limited because it was performed in only one HEI. This study may help managers to draw operation strategies, strengthening the $\mathrm{OC}$, and it contributes to the development of researches on OC by proposing the adaptation of the IBACO to the context of private HEIs.

Keywords: Organizational culture. Higher education institutions. Values and practices.

\section{RESUMEN}

Las organizaciones están compuestas de diferentes públicos que interactúan entre sí, formando su cultura organizacional (CO). Esta investigación analiza la CO de una IES privada - la IMED -, en la perspectiva de maestros, personal técnico-administrativo y estudiantes. Su naturaleza es cuantitativa y estadística descriptiva, adoptando el IBACO - Instrumento Brasileño para la Evaluación de la Cultura Organizacional, adaptado. Los resultados sugieren que la cultura de esta IES manifiesta su buena interacción con el público interno y con las fuerzas sociales, promoviendo un ambiente de convivencia agradable. Hay coherencia entre valores analizados y valores de la IMED y diferencias de percepción de valores y prácticas de la IES entre los públicos. La limitación de la investigación se evidencia en haber sido realizada en una única IES. Este estudio ayudará a gestores a trazar estrategias de actuación, fortaleciendo su $\mathrm{CO}$, y contribuye al avance en las investigaciones sobre $\mathrm{CO}$, al proponer la adaptación del IBACO al contexto de IES privadas.

Palabras clave: Cultura Organizativa. Institución de enseñanza superior. Valores y Prácticas.

\section{INTRODUÇÃO}

O contexto atual exige novos investimentos das organizações, seja em produtos e serviços, espaço físico, novas tecnologias ou recursos humanos, visando à sobrevivência e à obtenção de resultados sustentáveis (MORO et al., 2014). Entretanto, são as pessoas que constituem o fator central para alcançar competitividade, produtividade e excelência nas economias. As organizações apresentam diferentes realidades culturais, capazes de ser entendidas na perspectiva de seus diversos integrantes. A cultura organizacional resulta, portanto, de uma dinâmica cultural maior de seu meio social (HOFSTEDE, 1990).

\footnotetext{
É possível considerar uma organização como um agrupamento cultural, distribuído em diversos meios sociais, permitindo a construção de um elo
}

entre os graus de macro- e microestrutura: sociedade e empresa; coletividade e sujeito; empresa e sujeito; decisões e ações; discursos organizacionais e práticas; comportamento da organização e estratégias delineadas pela alta administração ～(SMIRCICH， 1983; JERMIER, 1991).

Este estudo examina a cultura organizacional em uma instituição de ensino superior (IES) privada do norte do Rio Grande do Sul. A cultura organizacional é aqui concebida com base em Hofstede (1991), para quem ela é holística, historicamente determinada, relacionada a conceitos antropológicos, socialmente construída e difícil de mudar. Pode-se ver a cultura organizacional como um dos determinantes da inovação, visto possuir elementos capazes de servir para reforçá-la ou inibi-la (GOMES, MACHADO e JOAQUIN, 2015). Alguns 
desses elementos são a legislação, a burocracia, a cultura e os diversos interesses organizacionais.

As IES são reconhecidas como organizações com cultura própria que, por meio de seu projeto educativo, transmitem seus valores organizacionais ao corpo discente. Elas (re)produzem e multiplicam culturas organizacionais. Da abordagem dessa realidade surgiu a motivação para o presente estudo, visando evidenciar como os professores, o quadro técnicoadministrativo e os alunos de uma IES percebem sua cultura organizacional. Buscou-se uma metodologia compatível com a investigação da cultura organizacional em uma IES, considerandoa uma das importantes instâncias condicionadoras de cultura e que viesse a servir de instrumento para a gestão da instituição enfrentar dificuldades e conflitos, relacionados tanto à adaptação externa quanto à integração interna. Assim se chegou à Escala IBACO, de Ferreira e Assmar (2008).

A identificação da cultura organizacional possibilita uma visão de como as pessoas se comportam, apresentam determinação no trabalho e aprendem, bem como de como o processo de mudança pode ser administrado para a consecução das metas propostas (SANTOS et al., 2004). Em consequência, formulou-se o objetivo do presente estudo: analisar, por meio de valores e práticas, as percepções culturais da IES, sob a perspectiva de diferentes públicos: professores, alunos e corpo técnico-administrativo. Como contribuição para a academia, ressalta-se a adaptação da escala IBACO para o contexto de IES privadas, incluindo o corpo discente e não apenas professores e funcionários, o que também justifica o estudo. No contexto brasileiro, não foi encontrado um questionário apto a ser aplicado aos alunos, os quais, ao permanecerem vários anos nas IES, ajudam a moldar sua cultura organizacional.

As IES necessitam realizar avaliações institucionais, e um dos aspectos a ser analisados diz respeito à forma como seus principais públicos avaliam seus serviços, ou seja, é essencial compreender como alunos, técnicos e professores percebem a imagem da instituição. $O$ presente estudo também se justifica devido à importância de entender a cultura organizacional, na perspectiva de diferentes públicos, inseridos no mesmo ambiente, porém com distintos cargos, atribuições, afazeres e mesmo objetivos diversos. Os achados desta pesquisa poderão auxiliar os gestores na definição de estratégias organizacionais que conduzam à excelência no ensino superior.

$$
\text { Inicialmente, apresenta-se o }
$$
arcabouço teórico, que aborda a cultura organizacional e a cultura no ensino 
superior. $\mathrm{Na}$ sequência, expõem-se o método utilizado na pesquisa, a análise e a discussão dos resultados, as considerações finais e as contribuições desta pesquisa.

\section{REFERENCIAL TEÓRICO}

O referencial teórico aqui se divide em duas partes: cultura organizacional e cultura no ensino superior.

\subsection{Cultura organizacional}

Uma cultura, segundo Geertz (1989), não possui lei específica ou diretriz para ser balizada. Ela é trabalhada no passar do tempo, sendo fruto da ação do homem. Aktouf (2007, p. 50) a visualiza como "um conjunto complexo e multidimensional de praticamente tudo o que constitui a vida em comum nos grupos sociais" e manifesta que a ela é "um movimento dialético inevitável entre atividade econômica, vida social e vida simbólica em que a infraestrutura (os fundamentos) sustenta e impregna as superestruturas (ideais, ideologias, conhecimentos, crenças, etc.)".

Schein (2009, p. 3), um dos mais tradicionais autores sobre o tema, entende que "cultura é uma abstração, embora as forças que são criadas em situações sociais e organizacionais que dela derivam sejam poderosas. Se não entendermos a operação dessas forças, nos tornamos suas vítimas". A cultura corporativa pode ser considerada como cultura organizacional. Esta se refere a valores e normas que permeiam toda a empresa ou parte dela (ARMSTRONG, 2006), e concerne também a crenças e atitudes (FURNHAM; GUNTER, 1993). No quadro 1, visualiza-se, através da evolução histórica, como estudiosos do tema entendem cultura organizacional.

Quadro 1 - Definições de cultura organizacional, na percepção de diversos autores

\begin{tabular}{|l|l|}
\hline Autor e ano & Definições \\
\hline Pettigrew (1979) & Um sistema de significados aceitos, que operam em dado momento. \\
\hline $\begin{array}{l}\text { Deal e Kennedy } \\
(1982)\end{array}$ & $\begin{array}{l}\text { Esta é intrínseca, produtos desta organização, sistemas, a missão da empresa, formas } \\
\text { de gestão e de recrutamento, recompensas e socialização. É a maneira como se fazem } \\
\text { 'as coisas'. }\end{array}$ \\
\hline Smircich (1983) & Um aderente social ou normativo, que fixa as partes de uma organização. \\
\hline Loesch (1986) & $\begin{array}{l}\text { As convicções compartilhadas dos gerentes de topo da empresa, sobre a maneira como } \\
\text { devem se controlar e controlar os funcionários e como conduzir os negócios. }\end{array}$ \\
\hline Pettigrew (1989) & $\begin{array}{l}\text { É percebida como um fenômeno no qual existem vários níveis. Em níveis mais } \\
\text { profundos a cultura é pensada como um conjugado de valores, crenças e hipóteses, } \\
\text { através do qual as organizações dão seguimentos a seus negócios. }\end{array}$ \\
\hline Bertero (1989) & $\begin{array}{l}\text { A cultura é visualizada sob a forma de valores, crenças e mitos; de um processo } \\
\text { relativamente longo de adaptação externa e integração interna da organização. Não há } \\
\text { como excluir as dimensões do ambiente impactando a cultura organizacional. }\end{array}$ \\
\hline
\end{tabular}




\begin{tabular}{|c|c|}
\hline Shein $(1992$, p. 9) & $\begin{array}{l}\text { Cultura da organização é um "[...] padrão de pressupostos básicos que o grupo criou, } \\
\text { descobriu ou desenvolveu, aprendendo a lidar com seus problemas de adaptação } \\
\text { externa e integração interna, os quais funcionam suficientemente bem, podendo, assim, } \\
\text { ser ensinados aos novos membros como o modo correto de perceber, pensar e sentir } \\
\text { em relação àqueles problemas". }\end{array}$ \\
\hline Hofstede (1984) & $\begin{array}{l}\text { Programação coletiva da mente, que distingue os membros de uma organização dos de } \\
\text { outra. A palavra programação indica as reações mais prováveis e compreensíveis, em } \\
\text { função do passado de cada um. }\end{array}$ \\
\hline Hofstede (1994) & $\begin{array}{l}\text { Demonstra aspectos da sociedade da qual a organização faz parte, não sendo possível } \\
\text { compreender a cultura de uma organização, sem conhecer o conjunto em que está } \\
\text { arraigada. Explicita ainda que todo ser humano é forjado pelo contexto em que está } \\
\text { inserido, não estando aberto à dinâmica humana nas organizações, sem conhecer a } \\
\text { cultura e a sociedade na qual está inserida. }\end{array}$ \\
\hline
\end{tabular}

Fonte: elaborado pelas autoras (2016).

Conforme mostra o Quadro 1, não há consenso sobre o conceito de cultura organizacional. Hofstede (1991) expõe que, para a maioria dos autores, a cultura organizacional é holística, historicamente determinada, conectada a conceitos antropológicos, socialmente construída e difícil de mudar. A cultura organizacional forma a base da organização e abrange todo o funcionamento de um grupo, influenciando em aspectos que compreendem o modo de relacionamento com a atividade central, as operações internas e os diversos ambientes (HOFSTEDE, 1990; MINTZBERG et al., 2000; SCHEIN, 2009). A cultura organizacional espelha, portanto, o universo empresarial (HOFSTEDE, 1991; CAMERON \& QUINN, 2006; SCHEIN, 2009), sendo considerada importante fator para gerar mudanças organizacionais e inovações.

As relações no ambiente organizacional mostram-se dinâmicas, permeadas por discursos, doutrinas, símbolos, valores, rituais, ideologias e crenças, que se desenvolvem sem imposição ao contexto social (MORGAN, 2002). Melhor entender a cultura leva a melhor entender as pessoas e as forças que atuam sobre elas, que definem como elas são e refletem os grupos com os quais cada um se identifica e dos quais deseja fazer parte (SCHEIN, 2009). A cultura organizacional exerce domínio sobre aqueles que trabalham em excelentes entidades. Quanto mais forte a cultura e mais dirigida ao mercado, menos necessidade há de manuais de política, organogramas, detalhamento de regras e procedimentos. Em organizações com estas características, os sujeitos, mesmo nas posições inferiores, sabem o que devem fazer, porque conhecem os valores da corporação (PETER; WATERMAN, 1982).

A cultura organizacional tornou-se tão usual quanto outros itens da estrutura organizacional, como estratégias e controles da organização (HOFSTEDE, 
1991). Srour (1998) explicita que a cultura é aprendida, transmitida e compartilhada, ou seja, a cultura não é inata ao homem e sim por ele absorvida do meio em que se encontra. Latham (2007), avaliza esse entrosamento, demonstrando como a cultura de uma sociedade, suas características de trabalho e a estrutura de um time reciprocamente se influenciam.

Em cultura organizacional, duas abordagens devem ser salientadas: a de Schein (1992), que enfatiza a cultura organizacional como resultado da dinâmica de determinada organização e a de Hofstede (1994), que a considera como resultado de uma dinâmica cultural maior da sociedade na qual determinada organização se insere. Torna-se, pois, imprescindível adotar um modelo de cultura que faça jus ao que a organização busca (SCHEIN, 1985).

A cultura organizacional, fenômeno existente em diferentes níveis, não é algo simples (PETTIGREW,1989; MORGAN, 2002). Em níveis mais aprofundados, a cultura é ponderada como um conjunto intricado de valores, crenças e pressupostos que norteiam as atitudes pelas quais uma organização conduz seus negócios. O cerne de crenças e pressupostos básicos são facilmente percebidos em manifestos, sistemas, símbolos, mitos e modelos de gratificação internos aos ambientes organizacionais. A cultura organizacional não se refere exclusivamente a indivíduos, seus relacionamentos e crenças, mas também a suas percepções sobre os resultados desta organização, seus sistemas, sua missão organizacional, suas formas de recrutamento, socialização e valorização (MORGAN, 2002).

Identifica-se a cultura organizacional através de valores e práticas organizacionais, sendo seu núcleo formado pelos valores (HOFSTEDE, 1990). As práticas organizacionais representam a camada mais visível da cultura e se expressa por símbolos, heróis e rituais (CALORI; SARNIN, 1991). Quando os membros de uma empresa partilham dos mesmos modelos, as tomadas de decisão e as escolhas são facilitadas, colaborando, em consequência, com o desenvolvimento das práticas organizacionais. Isto reforça a ideia que os valores instituem as crenças de uma organização, as quais são compartilhadas e levam ao desenvolvimento das práticas organizacionais (HOFSTEDE et al., 1990; TAMAYO; GONDIN, 1996).

Hofstede, (1990), Tamayo e Gondin, (1996), Meglino e Ravlin, (1998) e Verbeke (2000) sugerem uma definição sobre a contextualização de cultura organizacional muito similar, pois a ela atrelam a capacidade de reunir crenças e princípios, bem como tudo o que norteia a vida da empresa em relação às pessoas. Eles 
se referem aos comportamentos desejados, de interesse individual ou coletivo, os quais beneficiam as organizações, por serem os sujeitos quem dimensiona a cultura de uma organização. Meglino e Ravlin (1998) avaliam esta conjuntura entre empresa e seus sujeitos ou funcionários e a reputam como uma espécie de ideologia, na qual o comportamento dos sujeitos é norteados pelos vínculos que possuem vínculo com a organização.

A fim de conhecer uma cultura organizacional, pode-se mensurá-la por meio de questionários, contendo quesitos sobre, por exemplo, valores e práticas organizacionais. Diversos estudiosos empenham-se na operacionalização dos conceitos, com a proposição de escalas. Vários instrumentos, com diferentes características, estão à disposição para pesquisadores interessados no tema cultura organizacional, porém todos têm limitações em relação a seu âmbito de aplicação, à facilidade de uso ou às propriedades científicas (SCOTT et al., 2003). No Brasil, Ferreira et al. (2002) desenvolveram e validaram o Instrumento Brasileiro para Avaliação da Cultura Organizacional (IBACO). O estudo do modelo IBACO, no Brasil, foi apoiado no modelo de Calori e Sarnin (1991), aplicado na França, e no de Hofstede et al. (1990), aplicado na Dinamarca e na Holanda, possuindo semelhanças com o modelo de Tamayo e Gondim (1996). No Quadro 2, detalham-se os fatores que compõem a escala IBACO, que resultou de um estudo empírico, por meio do qual foram validados fatores, itens, escala de respostas e instruções (FERREIRA; ASSMAR, 2008).

Quadro 2 - Fatores do IBACO, 2008.

\begin{tabular}{|l|l|}
\hline $\begin{array}{l}\text { Valores de profissionalismo } \\
\text { cooperativo }\end{array}$ & $\begin{array}{l}\text { Relacionados à valorização dos colaboradores que executam suas tarefas } \\
\text { com eficácia e competência, demonstrando espírito de colaboração, } \\
\text { dedicação, profissionalismo e capacidade de iniciativa. }\end{array}$ \\
\hline $\begin{array}{l}\text { Valores de rigidez na estrutura } \\
\text { hierárquica de poder }\end{array}$ & $\begin{array}{l}\text { Referentes a valores presentes em organizações definidas por um sistema } \\
\text { de autoridade centralizado e autoritário que dificulta o crescimento } \\
\text { profissional e o reconhecimento do elemento humano. }\end{array}$ \\
\hline $\begin{array}{l}\text { Valores de profissionalismo } \\
\text { competitivo e individualista }\end{array}$ & $\begin{array}{l}\text { Denotam a valorização da competência, do desempenho e da eficácia } \\
\text { individuais na execução de tarefas para a obtenção dos objetivos } \\
\text { desejados. }\end{array}$ \\
\hline $\begin{array}{l}\text { Valores associados à satisfação e } \\
\text { bem-estar dos empregados }\end{array}$ & $\begin{array}{l}\text { Referentes à valorização do bem-estar, da satisfação e da motivação dos } \\
\text { colaboradores, isto é, da humanização do local de trabalho de modo a } \\
\text { torná-lo agradável e prazeroso. }\end{array}$ \\
\hline Práticas de integração externa & $\begin{array}{l}\text { Associados a práticas voltadas para o planejamento estratégico, a tomada } \\
\text { de decisão e o atendimento ao cliente externo. }\end{array}$ \\
\hline
\end{tabular}




(CONTINUAÇÃO)
\begin{tabular}{|l|l|}
\hline $\begin{array}{l}\text { Práticas de recompensa e } \\
\text { treinamento }\end{array}$ & $\begin{array}{l}\text { Relacionados a práticas vinculadas aos clientes internos e aos sistemas de } \\
\text { recompensas e treinamento adotados pela empresa. }\end{array}$ \\
\hline $\begin{array}{l}\text { Práticas de promoção do } \\
\text { relacionamento interpessoal }\end{array}$ & $\begin{array}{l}\text { Referente a práticas orientadas para a promoção das relações } \\
\text { interpessoais e satisfação dos colaboradores. }\end{array}$ \\
\hline
\end{tabular}

Fonte: adaptado de Ferreira e Assmar (2008).

\subsection{Cultura no ensino superior}

Diversas classificações pretendem explicar as diferenciações existentes entre as organizações e proporcionar seu melhor entendimento e de suas relações internas com o meio que as cerca. As IES estão classificadas conforme tipologias, sendo organizações complexas, que se apresentam de forma totalmente atípica, diferenciada de outras organizações, tanto quanto a seus aspectos estruturais, como às funções que devem desempenhar (ANDRIGUETO JUNIOR et al., 2011).

As IES são produtoras, reprodutoras e multiplicadoras de cultura. Ao realizarem seu projeto educativo, imprimem e transmitem valores, componentes significativos de uma cultura organizacional. Acessar estes valores significa conhecer instâncias condicionadoras de cultura (SANTOS et $a l ., 2004)$. Uma das formas de conhecer os valores organizacionais de uma IES é averiguar sua cultura organizacional, por meio dos depoimentos de seus dirigentes, professores, funcionários administrativos e alunos.

As IES particulares enfrentam problemas administrativos semelhantes aos das empresas modernas (ZANETIN, 2006), contudo seus desafios e conflitos alcançam outras proporções, devido ao perfil de seu público interno e externo, aliado a seus objetivos finais: o conhecimento $\mathrm{e}$ a educação. As IES sofrem a imposição de modelos e a interferência, em seus processos administrativos, de órgãos reguladores externos. Há intervenção das políticas do ensino superior, das reformas, das discussões sobre autonomia. Muitas IES são mantidas pela família fundadora, evidenciando traços de paternalismo e monólogos, o que influi diretamente em sua cultura e em seus processos. Elas também enfrentam preconceitos advindos do público externo com relação à qualidade do ensino produzido, já que, conforme a tradição nacional, as instituições públicas detêm o histórico e a tradição de excelência em ensino (ZANETIN, 2006).

Outro ponto interessante refere-se à presença do 'proprietário', uma vez que a 
cultura, a identidade e as relações de poder que permeiam as IES privadas refletem da identidade de seu 'dono'. A centralização de informações nos poucos que detêm o poder é um fato. A democratização provoca medo, ansiedade e conflitos (PENTEADO, 1998). Para o mesmo autor, a construção da identidade se alicerça no conhecimento da missão da IES, já que, inseridos na missão, estão os objetivos da instituição, contudo nem sempre os indivíduos conseguem defini-los com clareza e precisão e pouco vale definir formalmente a missão, sem a construção de sentidos, a partir de seu conceito.

As IES, através do processo educativo, compartilham de valores organizacionais, desde o fundador até os continuadores da obra, ou seja, dirigentes, corpo docente, corpo discente, funcionários.. Em geral, é o corpo discente que leva, para o ambiente externo, os valores da instituição, facilitando sua adaptação externa. Ele dissemina os valores compartilhados e comuns e os leva aos diversos segmentos sociais (SANTOS et al., 2004). As IES, segundo Rizzatti, Rizzatti Jr. e Sartor (2004), constroem seus modelos organizacionais a partir de características culturais próprias, apresentando diversidade de objetivos, alguns de difícil avaliação e mensuração. A difusão da autoridade e do poder de forma parcial provoca acentuadas fragmentações internas. Muitos conflitos resultam principalmente da elevada autonomia baseada na tradição, na especialização e na natureza de suas atividades.

No ambiente universitário, onde ocorrem interações sociais entre pessoas de diferentes regiões e países, a cultura emerge como uma das variáveis fundamentais para a compreensão do fenômeno organizacional. A cultura organizacional é o aspecto mais importante para o direcionamento das atividades da instituição. Ela se refere ao pensamento básico que orienta as ações de um gestor, determinando o caminho a ser seguido quando ele se deparar com várias alternativas de ação (ZONATTO et al., 2012).

Zonatto et al. (2012) referem que as IES apresentam liderança fracamente hierárquica, tendo o líder a função de catalisador e negociador no processo decisório. As organizações universitárias expõem muitos conflitos gerados por grupos internos e externos, que nela atuam e agem em conformidade com os próprios interesses. Muitos dos conflitos que ocorrem na IES originam-se tanto na complexidade de sua estrutura social e acadêmica quanto nos objetivos e valores complexos de grupos divergentes (ZONATTO et al., 2012). 
As IES privadas, a exemplo das demais organizações empresariais, podem se beneficiar da compreensão de sua cultura, a fim de traçar estratégias de atuação para enfrentar a intensa competição a que estão sujeitas. Conhecer a cultura organizacional da instituição auxilia os gestores no estabelecimento de ações que contribuam para o fortalecimento da IES como um todo.

\section{MÉTODO}

Este estudo tem como objeto a cultura organizacional de uma IES privada, a Faculdade Meridional IMED, localizada na região norte do Rio Grande do Sul, escolhida por sua representatividade regional, no contexto educacional e devido ao empreendedorismo, à excelência acadêmica e à inovação.

Para o alcance dos objetivos, foi adotada a estratégia de pesquisa quantitativa, utilizando técnicas de estatística descritiva, com análise fatorial e testes ANOVA, o que permitiu concluir quanto às diferenças e semelhanças de percepção sobre a cultura organizacional entre os três públicos investigados (professores, alunos e técnicoadministrativos). Realizou-se a triangulação dos dados com uma pesquisa documental, envolvendo informações relacionadas ao histórico institucional, à missão, à visão e aos valores da organização, a fim de ampliar o entendimento do problema pesquisado (CRESWELL, 2013).

Obtida a autorização da direção da IES para a realização da pesquisa, foi aplicado um pré-teste a sete respondentes. Efetuados os ajustes requeridos, iniciou-se a coleta de dados para a análise quantitativa. $\mathrm{O}$ instrumento de coleta de dados adotado foi um questionário preenchido pelos respondentes, sem inferência nem presença das pesquisadoras, conforme orientam Moreira e Caleffe (2006). A partir de revisão da literatura, Jung et al. (2009) identificaram setenta instrumentos para explorar a cultura organizacional e concluíram não existir um instrumento ideal para a explorar culturas organizacionais e que a escolha depende da razão e do contexto de aplicação. Levando em consideração tal assertiva, adotou-se o método quantitativo de levantamento dos dados, com base no IBACO - Instrumento Brasileiro para Avaliação da Cultura Organizacional, de Ferreira e Assmar (2008), concebido no contexto cultural brasileiro.

Para atender aos objetivos da pesquisa, o questionário IBACO foi adaptado e validado por especialista da área. Dos 94 itens originais, 40 fizeram parte do questionário aplicado neste estudo. 
Posteriormente, os questionários foram disponibilizados aos respondentes de forma on-line, pelo sistema Qualtrics, nos meses de junho e julho de 2016.

A amostragem foi não probabilística e contou com 544 questionários válidos, sendo 337 de alunos, 124 de professores e 83 de técnicos-administrativos. Dos respondentes, $54 \%$ são do sexo feminino. $\mathrm{Na}$ faixa etária entre 16 e 24 anos, estão $58 \%$ dos entrevistados e com idade igual ou acima dos 51 anos, estão 0,73\% deles. Em relação à escolaridade, $60 \%$ dos respondentes estão cursando o ensino superior; $62 \%$ são alunos; $20 \%$ possuem pós-graduação completa, estando estes diretamente vinculados ao segundo público de respondentes, os docentes $(33 \%$ do total). Quanto ao vínculo com a IES: $59 \%$ dos respondentes possuem em um período de um a três anos; $17 \%$, até um ano; 7,7\%, mais de sete anos com a instituição.

\subsection{Alterações efetuadas no IBACO}

Os itens do questionário utilizado neste estudo, com base no IBACO, de Ferreira e Assmar (2008), restaram distribuídos em seis fatores: três associados a 'valores' e três associados a 'práticas organizacionais':
1) valores de profissionalismo cooperativo - composto por 11 itens (n. 1, $6,8,14,15,38,52,56,76,82,87)$ relacionados à valorização dos empregados que executam suas tarefas com eficácia e competência, demonstrando espírito de colaboração, habilidade, dedicação, profissionalismo e capacidade de iniciativa, desse modo contribuindo para o alcance das metas comuns da organização;

2) valores de rigidez na estrutura hierárquica de poder - consiste de dois itens (n. 45,83$)$ referentes a valores presentes em organizações definidas por um sistema de autoridade centralizado e autoritário que dificulta o crescimento profissional e o reconhecimento do elemento humano;

3) valores associados à satisfação e ao bem-estar dos empregados - reúne seis itens (n. 16, 21, 34, 41, 42, 55) concernentes à valorização do bem-estar, da satisfação e da motivação dos empregados, isto é, à humanização do local de trabalho, de modo a torná-lo agradável e prazeroso;

4) práticas de integração externa composto de 10 itens (n. 7, 10, 19, 24, 25, 26, 28, 44, 49, 53) associados a práticas voltadas ao planejamento estratégico, à tomada de decisões e ao atendimento ao cliente externo, com foco, portanto, nos escalões superiores da organização; 
5) práticas de recompensa e treinamento - congrega sete itens (n. 3, 20, $36,39,54,59,88)$ relacionados a práticas vinculadas aos clientes internos e aos sistemas de recompensas e treinamento adotados pela empresa;

6) práticas de promoção do relacionamento interpessoal - consiste de quatro itens (n. 2, 30, 64, 80) referentes a práticas orientadas para a promoção das relações interpessoais e satisfação dos empregados, favorecendo, assim, a coesão interna.

\subsection{Observações sobre as alterações realizadas no questionário IBACO}

1) A redação de alguns itens foi modificada, sem alterar o sentido, para torná-los aplicáveis ao público interno e externo da Instituição. Neste estudo, o público externo é constituído pelos alunos.

2) Devido à finalidade da presente investigação, foram excluídos itens aplicáveis apenas ao público interno composto, neste estudo, pelos respondentes com vínculo empregatício com a IES -, já que se intencionava comparar as percepções da cultura organizacional manifestadas por diferentes públicos.

3) Os itens relacionados a valores de profissionalismo competitivo individualista, medidos no instrumento IBACO original, foram excluídos completamente do questionário utilizado, por não serem aplicáveis aos alunos da Instituição.

\section{ANÁLISE E DISCUSSÃO DOS RESULTADOS}

$\mathrm{Na}$ sequência, apresenta-se a instituição e analisam-se as informações obtidas na pesquisa.

\subsection{Contextualização da instituição}

A IES selecionada para esta pesquisa - Faculdade Meridional - IMED constitui-se como Sociedade Anônima de Capital Fechado e tem 12 anos de existência. Possui 311 empregados (211 docentes e 100 técnicos) e 5.342 alunos matriculados. Disponibiliza 10 cursos de graduação, 33 cursos de pós-graduação (especialização e MBAs) e três mestrados. Em 2016, foi considerada uma das melhores empresas para se trabalhar no RS, conforme a Revista Amanhã e o Instituto Great Place To Work (IMED, 2016). 


\subsection{Percepção dos colaboradores sobre os fatores da cultura organizacional}

Para analisar a percepção dos colaboradores da IES investigada em relação à cultura organizacional, utilizaramse os seguintes fatores: profissionalismo cooperativo, profissionalismo competitivo, satisfação e bem-estar dos empregados, prática de integração externa, prática de recompensa, treinamento e prática de promoção do relacionamento interpessoal, detalhados na subseção 3.1.

De acordo com os dados coletados, foram calculados as médias e os desviospadrão para cada variável, bem como a média e o Alfa de Cronbach do fator, como ilustrado na Figura 2.

Figura 2 - Média, desvio padrão e alfa de Cronbach das variáveis e fatores da cultura organizacional, na IMED, 2016.

\begin{tabular}{|c|c|c|c|c|}
\hline Fator & $\begin{array}{l}\text { Alpha de } \\
\text { Cronbach }\end{array}$ & Variável & Média & $\begin{array}{l}\text { Desvio- } \\
\text { Padrão }\end{array}$ \\
\hline \multirow{4}{*}{$\begin{array}{l}\text { Valores de } \\
\text { profissionalismo } \\
\text { cooperativo }\end{array}$} & \multirow{4}{*}{0,80} & $\begin{array}{l}1 \text { - Na IMED a cooperação é mais valorizada que a } \\
\text { competição }\end{array}$ & 3,54 & 1,16 \\
\hline & & $\begin{array}{l}2 \text { - Eu tenho ampla liberdade de acesso aos diretores na } \\
\text { IMED }\end{array}$ & 3,48 & 1,25 \\
\hline & & 3 - A minha dedicação é recompensada & 3,67 & 1,11 \\
\hline & & $\begin{array}{l}4 \text { - As ideias criativas são usadas para a obtenção de } \\
\text { melhores resultados com menos recursos }\end{array}$ & 3,69 & 1,00 \\
\hline \multirow{5}{*}{$\begin{array}{l}\text { Valores } \\
\text { associados à } \\
\text { satisfação e ao } \\
\text { bem-estar dos } \\
\text { empregados }\end{array}$} & \multirow{5}{*}{0,79} & 6 - As iniciativas individuais são estimuladas & 3,71 & 0,98 \\
\hline & & $\begin{array}{l}7-\mathrm{O} \text { atendimento às necessidades do aluno é uma das } \\
\text { metas mais importantes }\end{array}$ & 3,49 & 1,18 \\
\hline & & $\begin{array}{l}10 \text { - As necessidades pessoais e o bem-estar de todos } \\
\text { constituem uma preocupação constante da IMED }\end{array}$ & 3,62 & 0,99 \\
\hline & & $\begin{array}{l}11 \text { - Percebo que a IMED busca a excelência de seus } \\
\text { serviços como forma de satisfazer os alunos }\end{array}$ & 3,92 & 0,99 \\
\hline & & $\begin{array}{l}31 \text { - Investe-se em um bom ambiente com o objetivo de } \\
\text { garantir o bem-estar de todos }\end{array}$ & 3,89 & 0,99 \\
\hline \multirow[t]{3}{*}{$\begin{array}{l}\text { Práticas de } \\
\text { integração } \\
\text { externa }\end{array}$} & \multirow{3}{*}{0,70} & $\begin{array}{l}5 \text { - Tenho a noção clara dos principais objetivos da } \\
\text { IMED }\end{array}$ & 3,81 & 1,06 \\
\hline & & $\begin{array}{l}30 \text { - Eventos com distribuição de brindes são } \\
\text { comumente realizados }\end{array}$ & 3,20 & 1,28 \\
\hline & & $\begin{array}{l}33 \text { - O aniversário da IMED costuma ser comemorado } \\
\text { em conjunto com todos }\end{array}$ & 3,46 & 1,22 \\
\hline
\end{tabular}


(CONTINUAÇÃO)

\begin{tabular}{|c|c|c|c|c|}
\hline \multirow{6}{*}{$\begin{array}{l}\text { Práticas de } \\
\text { recompensa e } \\
\text { treinamento }\end{array}$} & \multirow{6}{*}{0,83} & $\begin{array}{l}12 \text { - As pessoas que apresentam ideias inovadoras } \\
\text { costumam ser premiadas }\end{array}$ & 3,52 & 1,12 \\
\hline & & 13 - A IMED investe no meu crescimento profissional & 3,83 & 1,06 \\
\hline & & $\begin{array}{l}20 \text { - A IMED premia quem apresenta um desempenho } \\
\text { superior aos demais }\end{array}$ & 3,25 & 1,21 \\
\hline & & $\begin{array}{l}21 \text { - O envolvimento com os ideais da IMED é uma } \\
\text { atitude bastante valorizada }\end{array}$ & 3,67 & 0,95 \\
\hline & & $\begin{array}{l}22 \text { - As inovações costumam ser introduzidas por meio } \\
\text { de treinamento }\end{array}$ & 3,46 & 1,02 \\
\hline & & $\begin{array}{l}23 \text { - Programas para aumentar a satisfação são } \\
\text { regularmente desenvolvidos }\end{array}$ & 3,51 & 0,97 \\
\hline \multirow{6}{*}{$\begin{array}{l}\text { Práticas de } \\
\text { promoção do } \\
\text { relacionamento } \\
\text { interpessoal }\end{array}$} & \multirow{6}{*}{0,82} & $\begin{array}{l}24 \text { - Procura-se manter uma atmosfera de segurança e } \\
\text { estabilidade }\end{array}$ & 3,84 & 1,00 \\
\hline & & $\begin{array}{l}34 \text { - As relações com os membros da direção são } \\
\text { cordiais e amigáveis }\end{array}$ & 3,78 & 1,05 \\
\hline & & $\begin{array}{l}36 \text { - As pessoas se relacionam como se fossem uma } \\
\text { grande família }\end{array}$ & 3,38 & 1,16 \\
\hline & & $\begin{array}{l}37 \text { - Os diretores que inovam e promovem mudanças } \\
\text { significativas são os modelos a serem seguidos }\end{array}$ & 3,75 & 1,02 \\
\hline & & $\begin{array}{l}39 \text { - As pessoas que se comprometem com a missão e } \\
\text { os ideais da IMED tornam-se modelos para os demais }\end{array}$ & 3,71 & 0,95 \\
\hline & & $\begin{array}{l}40 \text { - Existem normas que estabelecem o grau de } \\
\text { participação de todos no processo de tomada de decisão }\end{array}$ & 3,55 & 0,98 \\
\hline \multirow[t]{3}{*}{$\begin{array}{l}\text { Criatividade e } \\
\text { relacionamento }\end{array}$} & \multirow{3}{*}{0,71} & $\begin{array}{l}17 \text { - A IMED mantém relações amigáveis com os } \\
\text { alunos }\end{array}$ & 3,98 & 0,91 \\
\hline & & $\begin{array}{l}18 \text { - Prevalece um grande espírito de união entre as } \\
\text { pessoas na IMED }\end{array}$ & 3,72 & 1,09 \\
\hline & & $\begin{array}{l}19 \text { - Recebo treinamento para desenvolver minha } \\
\text { criatividade }\end{array}$ & 3,29 & 1,16 \\
\hline
\end{tabular}

Fonte: elaborado pelas autoras, com base nos dados da pesquisa, 2016.

Em relação ao desvio-padrão, identificou-se que a maioria das variáveis tiveram resultado próximo a um, demonstrando não haver discrepância entre as respostas. Na etapa de validação dos fatores da IBACO adaptada para este estudo, o Alfa de Cronbach obteve valores iguais ou superiores a $0,70 \mathrm{em}$ todos os 
construtos. De forma geral, um instrumento é classificado como tendo fiabilidade apropriada quando o $\alpha$ é, pelo menos, 0,70 (NUNNALLY, 1978). Entretanto, nas ciências sociais, um $\alpha$ de 0,60 é considerado aceitável, desde que se interpretem, com precaução, os resultados obtidos com o instrumento, além de levar em conta o contexto de computo do índice (DEVELLIS, 1991). Portanto, a adaptação da escala IBACO ao contexto de IES privada, incluindo os alunos, proposta neste estudo, mostra confiabilidade apropriada.

Utilizando-se as variações da escala Likert, de 1 (discordo totalmente) a 5 (concordo totalmente), os resultados demonstram que as variáveis de maiores médias entre os respondentes foram: "A IMED mantêm relações amigáveis com os alunos", com média de 3,98; "Percebo que a IMED busca a excelência de seus serviços como forma de satisfazer os alunos", representando média de 3,92; seguido de "Investe-se em um bom ambiente com o objetivo de garantir o bem-estar de todos" representando 3,89. Este resultado pode estar atrelado à formação da cultura organizacional que esta IES vem desenvolvendo em seus 12 anos de existência, pois a instituição tem por objetivo proporcionar um ambiente de trabalho harmonioso, no qual os empregados sintam prazer em trabalhar e encontrem reconhecimento e segurança, de modo que possam se desenvolver profissionalmente. Ela também prima pela excelência acadêmica (IMED, 2016).

O fator "Práticas de integração externa" está associado ao planejamento estratégico e ao atendimento ao cliente externo, com foco, portanto, nos escalões superiores da organização (FERREIRA; ASSMAR (2008). Assim as respostas à questão "Tenho a noção clara dos principais objetivos da IMED”, com média de 3,81, denotam que os públicos estão cientes das estratégias da Instituição, demonstrando alinhamento com a cultura da organização.

As variáveis que obtiveram as menores médias foram: "Eventos com distribuição de brindes são comumente realizados", com 3,20; “A IMED premia quem apresenta um desempenho superior aos demais", com média 3,25. Isso ocorreu porque a distribuição de brindes acontece em eventos especiais organizados pela IES. O desempenho superior é premiado junto ao 'público interno' e não aos alunos. “Recebo treinamento para desenvolver minha criatividade" obteve média 3,29 , o que pode estar associado ao não reconhecimento, pelos públicos, das práticas adotadas pela IES, com vistas a estes quesitos.

Em relação aos 'valores' da cultura organizacional, os fatores "integração externa" $(3,81)$ e "profissionalismo 
cooperativo" $(3,69)$ obtiveram as maiores médias. Estes resultados corroboram Ferreira e Assmar, 2008, de que são percebidos a vivência dos aspectos associados ao atendimento ao cliente; a dedicação; o profissionalismo; a capacidade de iniciativa, contribuindo para o alcance das metas da Instituição. Estes resultados estão em concordância com os valores cultivados pela IMED: excelência acadêmica, ética, inovação, meritocracia, empreendedorismo, desenvolvimento de pessoas, sustentabilidade e transparência (IMED, 2016).

$\mathrm{O}$ fator "Relacionamento e criatividade", aqui nominado especificamente, apresenta componentes pertencentes a outros fatores tanto do IBACO original quanto do adaptado a este estudo. Constatou-se a presença de informações pertencentes aos fatores: "Valores associados à satisfação e bemestar dos empregados", "Práticas de integração externa" e "Práticas de promoção do relacionamento interpessoal”. Uma explicação para este fato está na proximidade e na interação entre público interno e externo, que faz com que o entendimento do conteúdo das questões seja semelhante ou tenha importância similar para ambos, gerando um agrupamento independente. Por este motivo e para clarificar a explicação e seu uso futuro em ações gerenciais, este fator foi suprimido nas análises posteriores realizadas neste trabalho.

\subsection{Processo de análise dos dados}

A análise de fatores com método de extração por componentes principais e método de rotação varimax foi aplicada às variáveis iniciais do estudo em conjunto com o seguinte critério de escolha: (a) variáveis que apresentavam comunalidade maior que 0,5 e (b) participação em até dois fatores com pesos heterogêneos.

Em cada etapa, as variáveis que não se enquadravam nos critérios definidos foram excluídas do passo seguinte. Ao final, apenas 24 das 40 questões do IBACO adaptado foram utilizadas para cálculo das médias e posterior análise de variância para comparar os grupos de respondentes.

A análise final com cinco fatores, representa aproximadamente $62 \%$ da variância total explicada.

\subsection{Análises estatísticas das dimensões do IBACO}

Para estudar e entender as diferentes visões dos participantes da pesquisa em relação à IES e às dimensões do IBACO adaptado, foi realizada análise de variância 
(ANOVA), na qual foram comparados os diferentes públicos (professores, técnicoadministrativos e alunos) em relação à média dos valores observados no presente estudo. O valor de referência para cada grupo e dimensão foi obtido por média aritmética simples. Os resultados encontram-se expostos na Figura 3.

Figura 3 - Análise de variância - ANOVA

\begin{tabular}{|c|c|c|c|c|c|c|}
\hline & & $\begin{array}{l}\text { Soma dos } \\
\text { Quadrados }\end{array}$ & Gl & $\begin{array}{l}\text { Quadrado } \\
\text { Médio }\end{array}$ & $\mathrm{F}$ & Sig. \\
\hline \multirow{4}{*}{$\begin{array}{l}\text { Valores de profissionalismo } \\
\text { cooperativo }\end{array}$} & Entre Grupos & 30,420 & 2 & 15,210 & 20,498 &, 000 \\
\hline & Nos grupos & 401,446 & 541 &, 742 & & \\
\hline & Total & 431,867 & 543 & & & \\
\hline & Entre Grupos & 16,620 & 2 & 8,310 & 15,602 &, 000 \\
\hline \multirow{3}{*}{$\begin{array}{l}\text { Valores associados à satisfação e bem- } \\
\text { estar dos empregados }\end{array}$} & Nos grupos & 288,150 & 541 &, 533 & & \\
\hline & Total & 304,770 & 543 & & & \\
\hline & Entre Grupos & 72,044 & 2 & 36,022 & 47,803 &, 000 \\
\hline \multirow[t]{3}{*}{ Práticas de integração externa } & Nos grupos & 407,668 & 541 &, 754 & & \\
\hline & Total & 479,712 & 543 & & & \\
\hline & Entre Grupos & 27,460 & 2 & 13,730 & 24,823 &, 000 \\
\hline \multirow[t]{3}{*}{ Práticas de recompensa e treinamento } & Nos grupos & 299,241 & 541 &, 553 & & \\
\hline & Total & 326,702 & 543 & & & \\
\hline & Entre Grupos & 19,610 & 2 & 9,805 & 19,525 &, 000 \\
\hline \multirow{2}{*}{$\begin{array}{l}\text { Práticas de promoção do } \\
\text { relacionamento interpessoal }\end{array}$} & Nos grupos & 271,680 & 541 &, 502 & & \\
\hline & Total & 291,290 & 543 & & & \\
\hline
\end{tabular}

Gl= grau de liberdade; $F=$ Anova; Sig= significância.

Fonte: elaborado pelas autoras, 2016.

Houve diferença significativa ao nível de 5\% de significância para os grupos em todos os constructos. A partir disso, foi gerado um gráfico com o resumo das diferenças observadas (Figura 4). 
Figura 4 - Comparação entre os grupos de respondentes para cada dimensão do IBACO adaptado.

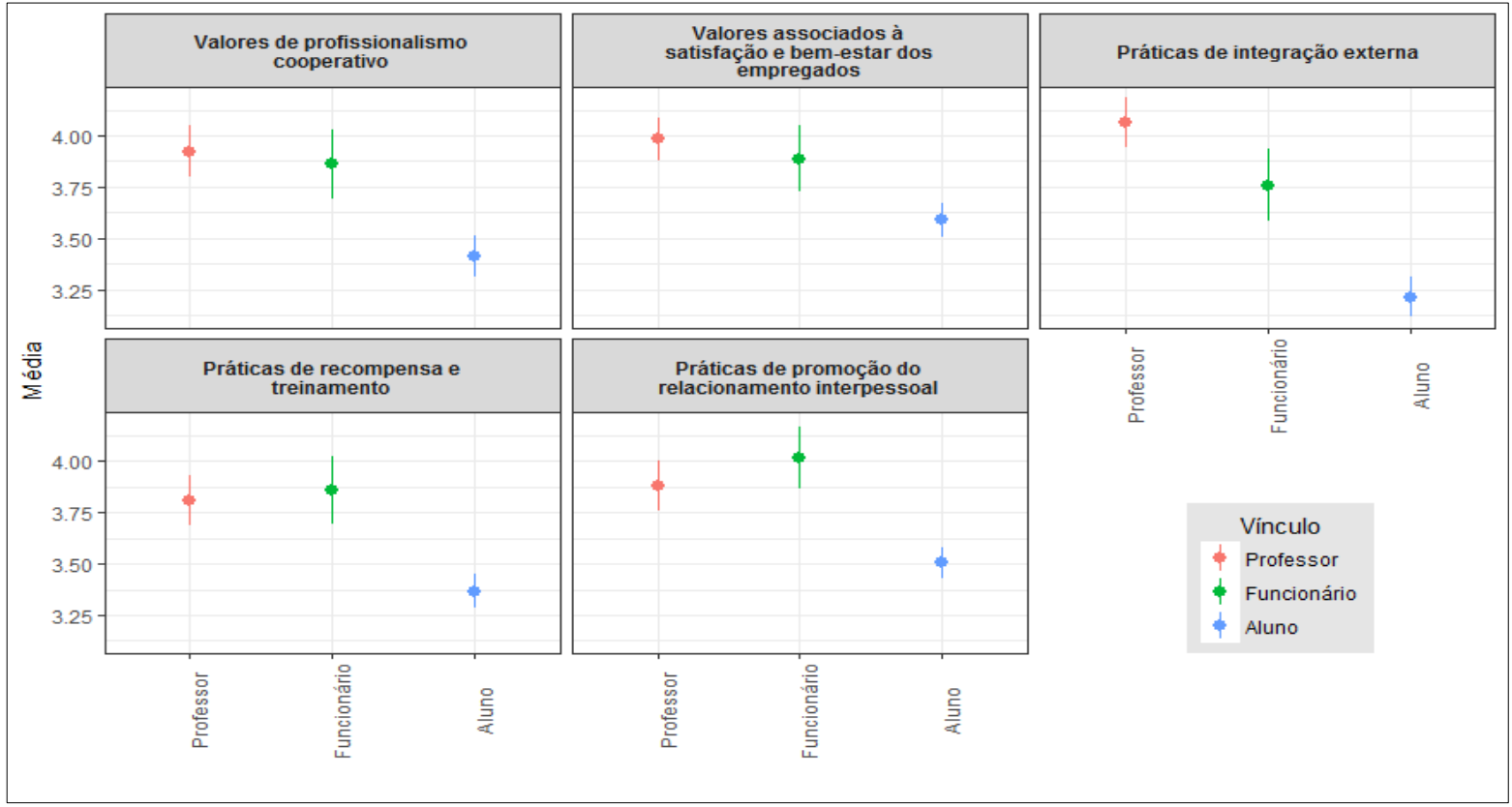

Fonte: elaborado pelas autoras, com base nos resultados da pesquisa, 2016.

Em todas as cinco dimensões calculadas e avaliadas para este estudo, a avaliação dos alunos foi sistematicamente menor do que os outros dois grupos internos (professores e técnicos-administrativos), sendo responsável pela fonte de variação e diferença observada na ANOVA. Pode-se atribuir esta diferença, em parte, ao contexto e à percepção da visão externa versus interna sobre a IES, no que se refere às práticas e aos valores e avaliados no IBACO adaptado.

$\mathrm{Na}$ visão interna, a avaliação média dos docentes sobre temas relacionados às dimensões "Valores de profissionalismo e cooperativo", "Valores associados à satisfação e bem-estar dos empregados" e "Práticas de integração externa" é maior que a avaliação média dos técnicoadministrativos, indicando que os docentes têm melhor percepção dos valores da IES, em relação ao quadro técnicoadministrativo.

A avaliação dos técnicoadministrativos é superior, em média, nos temas relacionados às dimensões "Práticas de recompensa e treinamento" e "Práticas de promoção do relacionamento interpessoal". Destas diferenças médias, apenas os valores obtidos para a dimensão "Práticas de integração externa" são estatisticamente diferentes entre si; professor versus funcionário ( $\mathrm{p}$-valor $=$ 0,043) e funcionário versus aluno ( $\mathrm{p}$-valor $=$ 0,000), sendo $p$-valor = significância . 


\section{CONSIDERAÇÕES FINAIS}

Segundo Schein (1989), a cultura organizacional é fundamentada em um padrão de premissas básicas, que se apresentam eficazes para solucionar problemas de adaptação externa e integração interna, as quais são e devem ser transmitidas por ensinamentos aos novos membros e a eles repassadas em diversas situações. Ressalta-se, pois, a relevância do presente estudo, que abordou a cultura organizacional de uma IES privada. Considera-se que foi atingido o objetivo de comparar as diferentes visões sobre a cultura organizacional, por meio da adaptação do IBACO e da aplicação de questionários, incluindo os alunos da IES. Embora não sendo o objetivo principal desta investigação, pondera-se que ela representa um avanço na literatura sobre o tema.

Mesmo não tendo sido analisados em profundidade os artefatos visíveis e os pressupostos básicos que compõem a cultura organizacional, os resultados sugerem que a cultura da IES manifesta sua boa interação com o público interno e com as forças sociais que permeiam suas relações, aqui representadas pelos alunos. Contudo, uma análise mais profunda dos elementos que compõem a cultura da instituição possibilitaria ampliar sua compreensão, incluindo aspectos simbólicos, histórias e rituais. Conforme Hofstede (1991), a cultura é socialmente constituída e difícil de mudar, daí a importância de identificar as percepções dos diferentes públicos e traçar estratégias para fortalecer a cultura organizacional, a fim de melhor enfrentar a acirrada concorrência que se impõe às IES privadas.

Percebeu-se coerência entre os valores analisados e os valores da IMED, cuja centralidade está em proporcionar um centro de excelência acadêmica para a formação de sujeitos capazes de compreender e transformar a realidade em que vivem (IMED, 2016).

Como uma limitação desta investigação, encontra-se sua estreita abrangência, pois ela foi realizada em uma única IES privada. Em consequência, este estudo não permite a generalização dos resultados. Sugere-se que, em trabalhos futuros, abranja-se mais de uma instituição de ensino superior, permitindo comparar a visão dos diferentes públicos em relação à cultura da própria instituição e de outras. Outras possibilidades são realizar estudo similar em diferentes regiões do Brasil, comparar IES públicas e privadas, bem como aplicar outras técnicas de análises e softwares diferentes.

Como contribuição gerencial, com base na avaliação média observada pelos 
professores, sugere-se a revisão dos itens relacionados às dimensões "Práticas de recompensa e treinamento" e "Práticas de promoção do relacionamento interpessoal". Apesar de a diferença não ser estatisticamente significativa, sinaliza a possiblidade de melhoria no ambiente interno da IES, que apresenta complexidade de estrutura tanto social como acadêmica, e nos objetivos e valores complexos dos grupos, algumas vezes até mesmo divergentes, como expõem Zonatto et al. (2012).

Em relação ao quadro técnicoadministrativo, destaca-se como ação prioritária a dimensão "Práticas de integração externa", pois ela apresenta diferença estatística significativa. As outras dimensões, que possibilitam ações são: "Valores de profissionalismo cooperativo" e "Valores associados à satisfação e bemestar dos empregados".

Entre as ações relacionadas aos alunos da IES, destaca-se a ação relacionada à dimensão "Práticas de integração externa", diretamente relacionada à interação deste segmento com a IES por meio do capital humano. Ações em outras dimensões têm potencial para melhorar a percepção dos alunos em relação ao tema que elas abordam.

Fazem-se necessárias a validação e a confirmação do instrumento IBACO adaptado para aplicação a outras organizações de pequeno porte, já que a escala IBACO foi validada e utilizada em organizações de médio e grande portes, conforme esclarecem Ferreira et al. (2002) e Ferreira e Assmar (2008). 


\section{REFERÊNCIAS}

AKTOUF, O. O simbolismo e a cultura de empresa: dos abusos conceituais às lições empíricas. In: CHANLAT, J. F. O indivíduo na Organização: dimensões esquecidas. São Paulo: Atlas, 2007.

ARMStRONG, M. A. Handbook of Human Resource Management Practice. 10. ed. London: Kogan Page, 2006.

BERTERO, C. Cultura organizacional e instrumentalização do poder. In: FLEURY, M. T. L. et al. Cultura e poder nas organizações. São Paulo, Atlas, 1989.

CAMERON, K. S.; QUINN, R. E. Kultura organizacyjna-diagnoza i zmiana: model wartości konkurujących. Oficyna Ekonomiczna, 2006.

CALORI, R.; SARNIN, P. Corporate culture and economic performance: a french study. Organization Studies, v. 12, n. 1, p. 49-74, 1991.

CRESWELL, J. W. Pesquisa de métodos mistos. 2. ed. Porto Alegre: Penso, 2013.

DEAL, T. E.; KENNEDY, A. A. Corporate cultures reading. MA: Addison-Wesley, 1982.

DEVELLIS, R. F. Scale Development: theory and applications. Newbury Park, CA: Sage Publications, 1991.

FERREIRA, M. C.; ASSMAR, E. M. L.; ESTOL, K. M. F.; HELENA, M. C. C. C.; CISNE, M. D. C. F. Desenvolvimento de um instrumento brasileiro para avaliação da cultura organizacional. Estudos de Psicologia, v. 7, n. 2, 2002.

FERREIRA, M. C.; ASSMAR, E. M. L. Cultura Organizacional: desenvolvimento de um instrumento brasileiro para avaliação da cultura organizacional. In: SIQUEIRA, M. M. M.(Org.). Medidas do comportamento organizacional: ferramentas de diagnóstico e de gestão. Porto Alegre: Artmed, 2008.

FURNHAM, F. A.; GUNTER, B. Corporate assessment: auditing a company's personality. London: Routledge, 1993.

GEERTZ, C. A Interpretação das Culturas. Rio de Janeiro: LTC, 1989. 
GOMES, G.; MACHADO, D., JOAQUIN, A. Determinantes da Cultura de Inovação: Estudo na Indústria Têxtil de Santa Catarina. Brazilian Business Review, p. 105-129, 2015.

HOFSTEDE, G. Cultural dimensions in management and planning. Asia Pacific journal of management, v. 1, n. 2, 1984.

HOFSTEDE, G.; HOFSTEDE, G. J.; MINKOV, M. Cultures and organizations: software of the mind. London: McGraw-Hill, 1991.

HOFSTEDE, G. Culture and organizations: software of the mind, intercultural cooperation and its importance for survival. London: Harper Collins, 1994.

HOFSTEDE, G.; NEUIJEN, B.; OHAYV, D. D.; SANDERS, G. Measuring organizational cultures: a qualitative and quantitative study across twenty cases. Administrative Science Quarterly, v.35, n.2, p. 286-316, 1990.

IMED. Institucional: missão, visão e valores. Passo Fundo: IMED, 2016. Disponível em: <https://www.imed.edu.br/institucional/Missao-visao-valores>. Acesso em: 25 jun. 2016.

JERMIER, J. M. Critical epistemology and the study of organizational culture: reflections on Street Corner Society. In: FROST, P. J.; MOORE, L. F.; LOUIS, M. R.; LUNDBERG, C. C.; MARTIN, J. (Eds.). Refraiming Organizational Culture. London: Sage, p. 254-270, 1991.

JUNG, T.; SCOTT, T.; DAVIES, H. T. O.; BOWER, P.; WHALLEY, D.; MCNALLY, R.; MANNION, R. Instruments for exploring organizational culture: A review of the literature. Public Administration Review. v. 69 n. 6 p. 1087-1096, 2009.

LATHAM, G. P. A. Speculative Perspective on the Transfer of Behavioral Science Findings to the Workplace "The Times They are A-Changin"”. Academy of Management Journal, v. 50, n. 5, p. 1027-1032, 2007.

LOESCH, J. W. Managing culture: The invisible barrier to strategic change. California Management Review, v. 28, p 95-109, 1986.

MOREIRA, H.; CALEFFE, L. G. Metodologia da pesquisa para o professor pesquisador. Rio de Janeiro: DP\&A, 2006.

MEGLINO, B. M.; RAVLIN, E. C. Individual values in organizations: concepts, controversies and research. Journal of Management, v. 24, n. 3, p. 351-389, 1998. 
MinTZBERG, H.; AHLSTRAND, B.; LAMPEL, J. Safári de estratégias. Porto Alegre: Bookmann, 2000.

MORO, A. B.; BALSAN, G. A. L.; COSTA, V. M. F.; SCHETINGER, M. R. C. Clima organizacional: fatores significativos na percepção de docentes e discentes vinculados a programas de pós-graduação. Revista Gestão Universitária na América Latina - GUAL, v. 7, n. 3, p. 01-21, 2014.

MORGAN, G. Imagens da organização. São Paulo: Atlas, 2002.

NUNNALLY, J. C. Psychometric theory. 2nd ed. New York: McGraw-Hill, 1978.

PENTEADO, S.T. Identidade e poder na universidade. São Paulo: Cortez, 1998.

PETER, T. J.; WATERMAN, R. H., Jr. In Search of Excellence: lessons from America's bestrun companies. New York: Harper \& Row, 1982.

PETTIGREW, A. M. On Studying Organizational Cultures. Administrative Science Quarterly, n.2 v. 4, 1979.

A Cultura das Organizações é Administrável? In: Fleury M. T. L.; Fischer, R. M. (coord). Cultura e Poder nas Organizações. São Paulo, Atlas, 1989.

RIZZATTI, G.; RIZZATTI, G. Jr.; SARTOR, V. V. B. Categorias de análise de clima organizacional em universidades federais. In: Colóquio Internacional sobre Gestão Universitária na América do Sul, IV, 2004, Florianópolis. Anais... IV Colóquio Internacional sobre Gestão Universitária na América do Sul, Florianópólis, 2004.

SANTOS, N. M. B. F.; ROSSO, M. J. U.; Mancini, M. Desvendando a cultura organizacional em Instituições de Ensino Superior. Revista Acadêmica Mutitemática - APG PUCSP, São Paulo, 2004.

SCHEIN, E. H. Organizational culture and leadership: A Dymamic View. San Francisco: Jossey-Bass, 1992.

SMR forum: How can organizations learn faster? The challenge of entering the green room. Sloan Management Review, v. 34, n. 2, p. 85, 1993. 
Three cultures of management: The key to organizational learning. MIT Sloan Management Review, v. 38, n. 1, p. 9, 1996.

Cultura Organizacional e Liderança. São Paulo, Atlas, 2009.

SCOTT, T., M., R.; DAVIES, H.; MARSHALL, M. The quantitative measurement of organizational culture in health care: a review of the available instruments. Health Services Research, v. 38, n. 3, 2003.

SMIRCICH, C. Concepts of culture and organizational analysis. Administrative Science Quarterly, Ithaca, v. 28, n. 3, 1983.

SROUR, R. H. Poder, cultura e ética nas organizações. Rio de Janeiro: Campus, 1998.

TAMAYO, A.; GONDIM, M. G. C. Escala de valores organizacionais. Revista de Administração, v. 31, n. 2, 1996.

VERBEKE, W. A revision of Hofstede et al.'s (1990) organizational practices scale. Journal of Organizational Behavior, v. 21, n. 5, 2000.

ZANETIN, R. Poder, Cultura e instituições de Ensino Superior Particulares (IES): desempenho e comunicação. Escola de Comunicações e Artes. Tese de doutorado PUCSP. São Paulo, 2006.

ZONATTO, V. C. S.; MACHADO, D. P. N.; LOURENSI, A.; BOGONI, N. M. Cultura organizacional em uma instituição de ensino superior: um estudo de caso sob as perspectivas propostas por Hofstede (1991). Revista Eletrônica de Administração e Turismo (ReAT), v. $1,2012$. 